\title{
The Effect of Soft Tissue on Detecting Hip Impingement
}

\author{
Mahshid Yazdifar \\ Mohammadreza Yazdifar \\ Ebrahim Esat \\ Brunel University, UK
}

doi: 10.19044/esj.2017.v13n18p57 URL:http://dx.doi.org/10.19044/esj.2017.v13n18p57

\begin{abstract}
Hip impingement is a hip associated abnormality and it reduces the activity of those affected and also it can result in osteoarthritis. Current clinical methods in detecting hip impingement known as FADIR test. This is a manual method and relies heavily on surgeons experience and the method is prone to error. The use of computational programmes are known to be more accurate and reliable as the kinematic of contact can easily be studied using the digitised bones of the hip joint assuming that the impingement is determined by bone to bone contact kinematics. Current impingement studies assume that the kinematics of hip joint can be studied by assuming the centre of rotation is fixed for hip joint. For highly conforming joints this assumption is acceptable but for cases where conformity is poor the presence of soft tissue and soft tissue loading becomes very important. The important need in orthopaedics field is to develop a model without too much simplification. All previous work on detecting impingement has ignored the factor of soft tissue.

In this paper for the first time the complete computational model of hip with soft tissue has been used to detect the impingement in a specific patient. In this paper the femur, acetabulum, cartilage and ligaments of specific patients were modelled in MIMICs using both MRI and CT scan. 3D hip models with and without soft tissues of normal hip, hip with impingement and hip with impingement after reshaping were modelled. The hip models were imported to detect impingement zone and impingement angle.

Our results show that the soft tissue in hip model affects hip impingement angle and hip biomechanics. This finding also shows that, if the boundary condition is closer to the real hip, then the results of computer-aided program will be more reliable.
\end{abstract}

Keywords: Hip Impingement, Soft Tissue, FADIR Test, Hip Biomechanics 


\section{Introduction}

Various studies have reported ROM preoperatively and postoperatively using 3D model of hip (Tannast, Kubiak-Langer, Langlo, Puls , Murphy , \& Siebenrock , 2007), (Kubiak-Langer, Tannast, Murphy , Siebenrock , \& Langlotz , 2007), (Bedi, et al., 2011), (Bedi, Dolan, Magenn, Lipman, Buly, \& Kelly, 2012), (Beaulé, Zaragoza, Motamedi , Copelan , \& Dorey, 2005). Results of computer simulation showed that range of motion can be improved after arthroscopic osteoplasty (Tannast, Kubiak-Langer, Langlo, Puls , Murphy , \& Siebenrock , 2007), (Kubiak-Langer, Tannast , Murphy , Siebenrock , \& Langlotz , 2007), (Bedi, et al., 2011), (Bedi, Dolan, Magenn, Lipman, Buly, \& Kelly, 2012). The measurement of only alpha angel is not alone enough for detecting the benefits of arthroscopy (Bedi, et al., 2011), (Bedi, Dolan, Magenn, Lipman, Buly, \& Kelly, 2012). Reduction in motion is one of the impingement affect that can help to diagnosis the impingement (Bagwell, et al., 2016). The identification of impingements and preoperative assessment can assist surgeons in making decisions to ascertain operative treatments (Kubiak-Langer, Tannast, Murphy , Siebenrock , \& Langlotz , 2007). Entire dislocation for observing patho-mechanism is not necessary, as the causes of impingement can be found preoperatively (Lavigne , Parvizi , Beck, Siebenrock , Ganz, \& Leuning, 2004). Some invasive approaches like arthroscopy can be used for carrying out surgical procedure of FAI, only if amount of bone to be removed is established preoperatively (Kubiak-Langer, Tannast, Murphy, Siebenrock , \& Langlotz , 2007).

Some research articles have shown bespoke software can be an effective tool in identifying impingement diseases preoperatively (KubiakLanger, Tannast, Murphy, Siebenrock , \& Langlotz, 2007), (Hu, Langlotz, Lawrence , Langlotz , \& Nolte , 2001), (Kang , Sadri, Moccozet, \& Magnenat-Thalmann , 2002).

The CT based models can assist surgeons to detect the impingement zone accurately and in less invasive method (Tannast, Langlotz , Siebenrock, Wiese, Bernsmann , \& Langlotz , 2005), (Brunner , Horisberger, \& Herzog , 2009), (Monahan \& Shimada , 2008), (Pearle, Kendoff , \& Musahl , 2009), (Rivkin \& Liebergall , 2009). The collision detection algorithms based on CT was able to calculate the range of motion, establish volume of resection and offered right information on pre and post-operative locations of FAI as well as impingement angle (Bedi, et al., 2011), (Bedi, Dolan, Magenn, Lipman, Buly, \& Kelly, 2012). It has been found that surgical measures for treating FAI are more beneficial to patients and surgeons both. Hip joint's dislocation is surgically not essential for observing patho-mechanicsm of hip joint's diseases (Kubiak-Langer, Tannast, Murphy , Siebenrock, \& Langlotz, 2007). 
The lesions on impingements and damaging in soft tissues reduce range of motion. CT based computer models can identify the regions of impingements within symptomatic-patients (Bedi, et al., 2011), (Bedi, Dolan, Magenn, Lipman, Buly, \& Kelly, 2012). The osteoplasty surgery in impingement regions enhance range of motion and reduce the intermittent collisions and chondral injuries in FAI zone (Bedi, et al., 2011), (Bedi, Dolan, Magenn, Lipman, Buly, \& Kelly, 2012). On the basis of some clinical research, it was reported that FAI limits adduction, internal-rotation and flexion (Jäger , Wild, Westhoff , \& Krauspe, 2004), (Leunig, Podeszwa , Beck, Werlen , \& Ganz, 2004), (Siebenrock, Schöniger , \& Ganz , 2003).

Table 1 presents ROM which has been shown by some researchers with the use of computer based programmes.

Table 1: Range of motion for normal hip, hip with impingement and hip with impingement after reshaping (Kubiak-Langer, Tannast, Murphy, Siebenrock , \& Langlotz , 2007)

\begin{tabular}{cccc}
\hline Parameter & Normal hip & FAI (preoperative) & $\begin{array}{c}\text { FAI (after } \\
\text { reshaping) }\end{array}$ \\
\hline Flexion & $122^{\circ} \pm 16.3^{\circ}$ & $105.2^{\circ} \pm 12.2^{\circ}$ & $125.4^{\circ} \pm 9.7^{\circ}$ \\
Extension & $56.5^{\circ} \pm 20.1^{\circ}$ & $61.1^{\circ} \pm 31.8^{\circ}$ & $71.1^{\circ} \pm 26.4^{\circ}$ \\
Abduction & $63.3^{\circ} \pm 10.9^{\circ}$ & $51.7^{\circ} \pm 12.2^{\circ}$ & $63.6^{\circ} \pm 7.5^{\circ}$ \\
Adduction & $32.7^{\circ} \pm 12.3^{\circ}$ & $34.6^{\circ} \pm 12.3^{\circ}$ & $35.8^{\circ} \pm 15.3^{\circ}$ \\
$\begin{array}{c}\text { Internal rotation in } 90^{\circ} \\
\text { flexion }\end{array}$ & $35.2^{\circ} \pm 6.9^{\circ}$ & $11.1^{\circ} \pm 6.9^{\circ}$ & $35.8^{\circ} \pm 15.3^{\circ}$ \\
$\begin{array}{c}\text { External rotation in } 90^{\circ} \\
\text { flexion }\end{array}$ & $102.5^{\circ} \pm 14.2^{\circ}$ & $83^{\circ} \pm 33.7^{\circ}$ & $93.9^{\circ} \pm 32.7^{\circ}$ \\
\hline
\end{tabular}

The non-invasive type of assessment is necessary for recommendation of suitable treatments and detecting impingement (Tannast, Kubiak-Langer, Langlo, Puls , Murphy , \& Siebenrock , 2007). Reliable and correct simulation is quite important (Tannast, Kubiak-Langer, Langlo, Puls , Murphy , \& Siebenrock , 2007). The computer based analysis is matched with the clinical analysis data on range of motion in impingement (Eijer , Myers , \& Ganz , 2001), (Jäger , Wild , Westhoff , \& Krauspe, 2004), (Leunig, Podeszwa , Beck , Werlen , \& Ganz, 2004), (Siebenrock , Schöniger, \& Ganz , 2003), (Strehl \& Ganz , 2005), (Wettstein \& Dienst , 2006).

Tannast et al. (Tannast, Kubiak-Langer, Langlo, Puls , Murphy , \& Siebenrock , 2007) developed non-invasive 3D assessment of FAI called "Hip Motion" (Tannast, Kubiak-Langer, Langlo, Puls , Murphy , \& Siebenrock , 2007). This computer simulation detects impingement angle and impingement zone and also measures ROM of hip joint (Tannast, Kubiak-Langer, Langlo, Puls , Murphy , \& Siebenrock , 2007). They had two groups of 3D model; normal and impingement (Tannast, Kubiak-Langer, Langlo, Puls , Murphy , \& Siebenrock , 2007). They validated their computer simulation method with cadaver samples. The bespoke program 
overestimated ROM compared to the cadaver samples (Tannast, KubiakLanger, Langlo, Puls , Murphy , \& Siebenrock , 2007). One of the main limitations of his method "Hip Motion" program is not applicable for largely dysplastic hips with a shallow acetabulum where an unambiguous centre of rotation cannot be found (Tannast, Kubiak-Langer, Langlo, Puls , Murphy , \& Siebenrock , 2007). In addition, it cannot be used for hips with advanced osteoarthritis because joint space narrowing leads to a change in the femoral head centre relative to the acetabulum, resulting in a nonconcentric joint morphology" (Tannast, Kubiak-Langer, Langlo, Puls , Murphy , \& Siebenrock , 2007).

Kiubic Langer et al. (Kubiak-Langer, Tannast, Murphy, Siebenrock , \& Langlotz , 2007) used "Hip Motion" program to measure ROM of normal, FAI after and before operation. They claimed that there is significant reduction of flexion, adduction and internal rotation in hip diagnosed with FAI (Kubiak-Langer, Tannast , Murphy , Siebenrock , \& Langlotz , 2007). Also their findings showed that there is $5^{\circ}-8^{\circ}$ improvement in internal rotation, $15^{\circ}-20^{\circ}$ improvement in flexion and $1^{\circ}-4^{\circ}$ improvement in adduction after operation. However impingement zone remained the same (Kubiak-Langer, Tannast , Murphy , Siebenrock , \& Langlotz , 2007). They claimed that information obtained by using "Hip Motion" program combined with arthroscopy can replace hip dislocation which is a major hip operation (Kubiak-Langer, Tannast , Murphy , Siebenrock , \& Langlotz , 2007).

Tannast et al. (Tannast, Goricki, Beck, Murphy, \& Siebenrock, 2008) used "Hip Motion" program to find impingement locations for several patients and compared the results with hip dislocation (Tannast, Goricki, Beck, Murphy, \& Siebenrock, 2008). Their results showed that the hip impingement zone is the same for FAI hips in both methods: computer simulation and hip dislocation surgery (Tannast, Goricki, Beck, Murphy, \& Siebenrock, 2008).

Chegini et al. (Chegini, Beck, \& Ferguson, 2009) studied the effect of hip morphology on stress distribution on hip cartilage during daily activities in patients with hip impingement. They used CAD program to make 3D model of hip with different $\mathrm{CE}$ angle and then they analysed stress distribution in FEA (Chegini, Beck, \& Ferguson, 2009). Their finding showed that higher $\mathrm{CE}$ angles cause higher contact peak pressure. However, the place of peak pressure remains the same for all CE angles (Chegini, Beck, \& Ferguson, 2009). They also found that stress in hip cartilage are higher when walking than standing also stress level on hip cartilage are higher when seating than walking. The stress in seating is higher as needed to have higher rotation (Chegini, Beck, \& Ferguson, 2009). They concluded 
that stress and peak pressure on hip cartilage depends on joint geometry, motion and load (Chegini, Beck, \& Ferguson, 2009).

Asheesh bedi et al. (Bedi, et al., 2011), (Bedi, Dolan, Magenn, Lipman, Buly, \& Kelly, 2012) developed computer-assisted 3D modelling of hip to measure ROM of hip. Their computer-assisted model did not have centre of rotation and that small load on head of the femur controls hip rotation. Their finding showed that ROM improved in FAI patients after surgery (Bedi, et al., 2011), (Bedi, Dolan, Magenn, Lipman, Buly, \& Kelly, 2012).

It follows, therefore, there are many limitations which can be specified for previous studies;

a) Soft tissues were not used in the hip models studied computationally for impingement detection ( $\mathrm{Hu}$, Langlotz , Lawrence , Langlotz , \& Nolte, 2001), (Kang , Sadri, Moccozet, \& Magnenat-Thalmann , 2002), (Kubiak-Langer, Tannast , Murphy , Siebenrock , \& Langlotz , 2007), (Bedi, et al., 2011), (Bedi, Dolan, Magenn, Lipman, Buly, \& Kelly, 2012). Mantovani et al. mentioned that hip joint centre has main effect on motion analysis (Mantovani, et al., 2016). Soft tissue affects surgical interventions and even post-surgical muscular reconditioning. The impingement has been found as a bone to bone contact.

b) Effects of rotation centres are not validated by these previous researchers and they thought that rotation centres are fixed and these are at the centre part of femur (Kubiak-Langer, Tannast, Murphy, Siebenrock , \& Langlotz , 2007).

c) Previous researchers do not provide enough information on the measurement technique deployed and the accuracy of current methods are not considered (Kennedy, Lamontagne, \& Beaulé , 2009).

\section{Method}

\section{Case studies}

The CT and MRI of two patients were taken. The patient with impingement had two sets of data before and after operation.

Case 1: A male with age of 42 and diagnosed with Cam impingement on his left hip. The height of $1.75 \mathrm{~m}$ and weight of $74 \mathrm{Kg}$ were reported. The $\mathrm{CT}$ and MR images were taken after and before reshaping operation so two sets of data were available for this volunteer. Case 1 had two CT and MRI data before and after surgery.

Case 2: A male with age of 38 and diagnosed with normal hip. The height of $1.8 \mathrm{~m}$ and weight of $78 \mathrm{Kg}$ were reported. The CT and MR images were taken. 


\section{Boundary condition}

After tacking the CT and MRI from cases then 3D hip models of hip with and without soft tissue (Figure 1) was created in MIMICs. The 3D models was imported in Abaqus. The boundary condition was applied according to the previous articles (Russell, Shivanna, Grosland, \& Pedersen, 2006), (Philips , Pankaj , Howie, Usmani , \& Simpson, 2007). Three angles which are measured in FADIR test are measured in FEA for normal hip, hip with impingement and hip with impingement after reshaping operation.

a
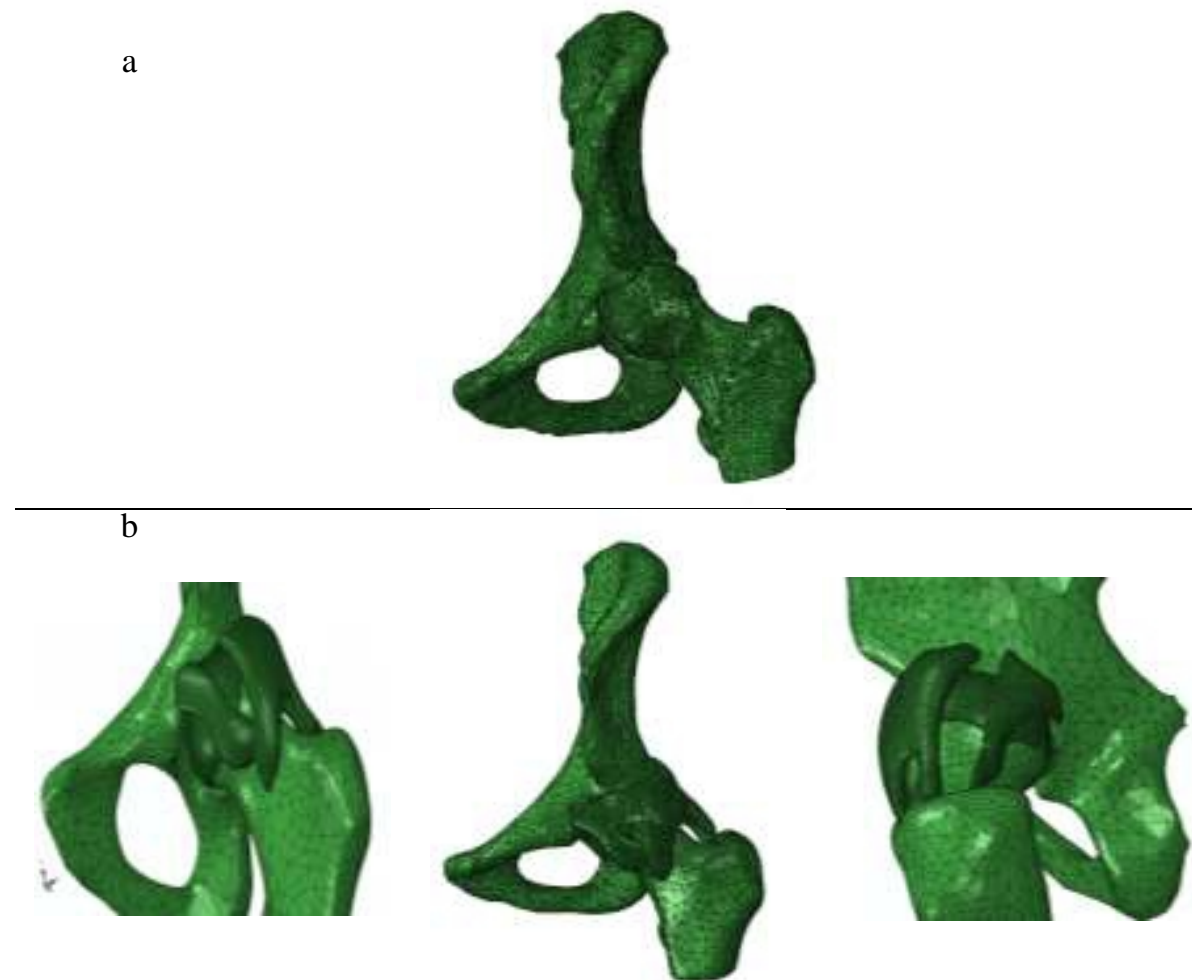

Figure 1: Assemble of hip model a) without soft tissues b) with soft tissues

\section{Impingement angle (FADIR test)}

Angle of impingement evaluation used in this thesis is based on FADIR test. FADIR test are included with 3 different angles: Flexion, Adduction in $90^{\circ}$ flexion and Internal Rotation in $90^{\circ}$ flexion. These three angles are measured and reported as impingement angle.

The flexion angle is the maximum flexion that hip can have. The adduction angle in $90^{\circ}$ flexion is the maximum angle of adduction while hip is in $90^{\circ}$ flexion. To measure the adduction in $90^{\circ}$ flexion, first hip flexed until $90^{\circ}$ and then adducted until maximum angle. The maximum angle is the adduction angle. The internal rotation angle in $90^{\circ}$ flexion is the maximum angle of internal rotation while hip is in $90^{\circ}$ flexion. 
In this paper to calculate impingement angle the hip joint centre was chosen as a centre of coordinate. The $Z$ axis was chosen parallel to the femur shaft. The $X$ axis was chosen parallel to the horizontal hip line. The $Y$ axis was automatically changed perpendicular to the $X$ and $Z$ axis.

Impingement angle which is presented in this study is comprised of three angles. The impingement angles are the angles measured in FADIR test. FADIR test was simulated in this study. The first angle was maximum flexion which was the rotation of femur around $X$ axis called $U R_{1}$ in Abaqus. The femur was rotated around $X$ direction to obtain the first angle of impingement. The second angle was the maximum adduction in $90^{\circ}$ flexion which was the rotation of femur around $Y$ axis called $U R_{2}$ in Abaqus. The femur was rotated around $X$ axis $90^{\circ}$ then was rotated around $Y$ direction to obtain the second angle of impingement. The third angle was the maximum internal rotation in $90^{\circ}$ flexion which was the rotation of femur around $Z$ axis called $U R_{3}$ in Abaqus. The femur was rotated around $X$ axis $90^{\circ}$ then was rotated around $Z$ direction to obtain the third angle of impingement.

\section{Impingement zone (clock method)}

The impingement zone which is used is based on the clock method. This method is based on the place of impingement in acetabulum according to the clock. The clock method is based on a clock fixed on acetabulum from 1 to 12 and the place of impingement is reported by the time shown in the clock. The place of impingement in acetabulum according to Ganz et al. (Ganz, Parvizi, Beck, Leunig, Nötzl, \& Siebenrock, 2003) is the place of internal rotation in $90^{\circ}$ flexion. This is when impingement pain in the hip is felt by the patient. The place of impingement on the acetabulum is also called impingement zone. Anterior view of acetabulum shows time 3 and in the clock method and posterior view of acetabulum shows time 9 in the acetabulum.

\section{Collision detection of impingement}

One simple way of studying the location of impingement is to perform collision detection by applying joint motion and extending it until it collides. Many articles (Hu , Langlotz, Lawrence, Langlotz , \& Nolte , 2001), (Kubiak-Langer, Tannast, Murphy, Siebenrock , \& Langlotz , 2007), (Bedi, et al., 2011), (Bedi, Dolan, Magenn, Lipman, Buly, \& Kelly, 2012), (Tannast, Kubiak-Langer, Langlo, Puls , Murphy , \& Siebenrock , 2007) studied the range of motion for hip with impingent to help surgeons using collision detection methods. Collision detection involves determining when one object penetrates another. It is clearly an expensive proposition as this is performed in an incremental fashion, particularly when large numbers of 
objects are involved and objects have complex shape (Moore \& Wilhelms, 1988).

The goal of collision detection in a FEA software (also known as interference detection, contact determination, or impingement detection) is to automatically report a geometric contact when it is about to occur or has actually occurred (Lin \& Manocha, 1995). There are two classes of collision detection methods. The first kind determines whether the surfaces of objects intersect (Moore \& Wilhelms, 1988). In the first model, surfaces are modelled as a grid of points connected to form triangles. Collision between surfaces are detected by testing for penetration of each vertex point through the planes of any triangle not including that vertex. The surface are assumed to be initially separate. For each time step of animation, the positions of points at the beginning and the end of the time step must be compared to see if any point went through a triangle during that time step. If so a collision has occurred (Moore \& Wilhelms, 1988). The second is based on the calculation of distances between objects, because two objects are separate if they have a positive distance from each other (Lin \& Manocha, 1995). The heart of their collision detection algorithm is a simple and fast incremental method to compute the distance between two polyhedral. It utilizes convexity to establish some local applicability criteria for verifying the closest feature to constant size and thus guarantee expected constant running time for each test (Lin \& Manocha, 1995).

The method developed in this paper for collision detection is based on the stress-impingement angle diagram. When two objects in the space have not impinged, the contact stress between them is zero. As soon as two objectives are impinged, the contact stress starts to increase. In the diagram of stress-impingement angle the point where stress starts to increase from 0 , is the impingement angle. As soon as the impingement happen the stress is not zero so that angle is claimed as an impingement angle.

Abaqus was used to detect impingement angle and impingement area. Flexion, adduction, and internal rotation were defined for each model. Femur rotates around fixed centre and hit the acetabular in the certain impingement angle. Flexion is defined to vary between $0-180$ which 0 is when femur is in position of $0^{\circ}$ of flexion 180 was the maximum flexion.

\section{Adjustable goniometer}

The ROM test (Flexion, adduction in $90^{\circ}$ of flexion, internal rotation in $90^{\circ}$ of flexion) was measured by adjustable goniometer for volunteer without impingement. A simple long-arm goniometer with $360^{\circ}$ scale was used in this study. The volunteers go under the FADIR test to measure flexion, adduction in $90^{\circ}$ of flexion and internal rotation in $90^{\circ}$ of flexion. Figure 78 a shows how flexion was measured by goniometer. One arm of the 
goniometer was aligned with femur in the supine position in the lateral view and the other one was fixed in the maximum flexion. One arm of the goniometer was aligned with femur in $90^{\circ}$ of flexion in the anterior view and the other one was fixed in the maximum adduction in $90^{\circ}$ of flexion to measure adduction. One arm of the goniometer was aligned with fibula in the $90^{\circ}$ of flexion in the anterior view and the other one was fixed in the maximum internal rotation in $90^{\circ}$ of flexion to internal rotation.

\section{Results}

In this section all experiments conducted on the model with and without tissues are repeated with tissues attached. The simulation results of FEA for fixed centre of rotation hip models, different centre of rotation hip models, free centre of rotation hip models and hip models with soft tissues are presented for all three hip models (normal hip, hip with impingement and hip with impingement after reshaping). Figure $2 \mathrm{a}$ shows the normal volunteer hip model flexion when the centre of rotation is fixed. Figure $2 b$ presents the normal volunteer hip model flexion when centre of rotation is free. Figure $2 \mathrm{c}$ shows the normal volunteer hip model flexion when the soft tissues are included in the hip model.

Table 2 presents the range of motion regarding flexion, adduction and internal rotation after reshaping, and compared to the impinged hip. The results are consistent with the findings of Kubiak-Langer et al. (KubiakLanger, Tannast , Murphy, Siebenrock , \& Langlotz , 2007) who stated that the range of motion improves after a surgical operation (Table 1). The results of our collision detection findings and previous work (KubiakLanger, Tannast, Murphy, Siebenrock , \& Langlotz , 2007) and our results are similar to those found in these articles $(\mathrm{p} \leq 0.001)$. This outcome confirms that our results are in line with previously published literature.

Table 2 gives the range of motion for normal, impinged and reshaped hip when the centre of rotation is free. Table 2 indicates the results of impingement angle when the centre of rotation is not defined for normal, impinged and reshaped hip. Table 3 shows the comparison of our free centre of rotation results with previous studies (Bedi, et al., 2011) (Bedi, Dolan, Magenn, Lipman, Buly, \& Kelly, 2012).

Table2: Results of different boundary conditions

\begin{tabular}{c|ccc|ccc|ccc}
\hline & \multicolumn{3}{c}{ Flexion } & \multicolumn{3}{c}{ Adduction } & \multicolumn{3}{c}{ Internal Rotation } \\
\hline & Normal & Imping & Reshape & Normal & Imping & Reshape & Normal & Imping & Reshape \\
\hline $\begin{array}{c}\text { Fixed centre of } \\
\text { rotation }\end{array}$ & 115 & 105 & 120 & 27 & 24 & 29 & 30 & 24 & 36 \\
\hline $\begin{array}{c}\text { Free centre of } \\
\text { rotation }\end{array}$ & 105 & 91 & 120 & 32 & 36 & 47 & 8 & 10 & 15 \\
\hline $\begin{array}{c}\text { Hip with soft } \\
\text { tissues }\end{array}$ & 139 & 120 & 146 & 40 & 23 & 45 & 30 & 19 & 33 \\
\hline
\end{tabular}


Table 3: Range of motion in free centre of rotation models according to the previous articles (Bedi, et al., 2011) (Bedi, Dolan, Magenn, Lipman, Buly, \& Kelly, 2012)

\begin{tabular}{ccc}
\hline & Flexion & Internal Rotation \\
\hline Hip with impingement & $107 \pm 11$ & $19 \pm 13$ \\
Reshaped hip & $111 \pm 11$ & $28.4 \pm 12$ \\
\hline
\end{tabular}

Figure 2 also confirms that impingement zone is at 11 o'clock for free and fixed centre of rotation. However, for the free centre of rotation there is also impingement at 6 o'clock. This may occur because of free motion of the femur in all direction.

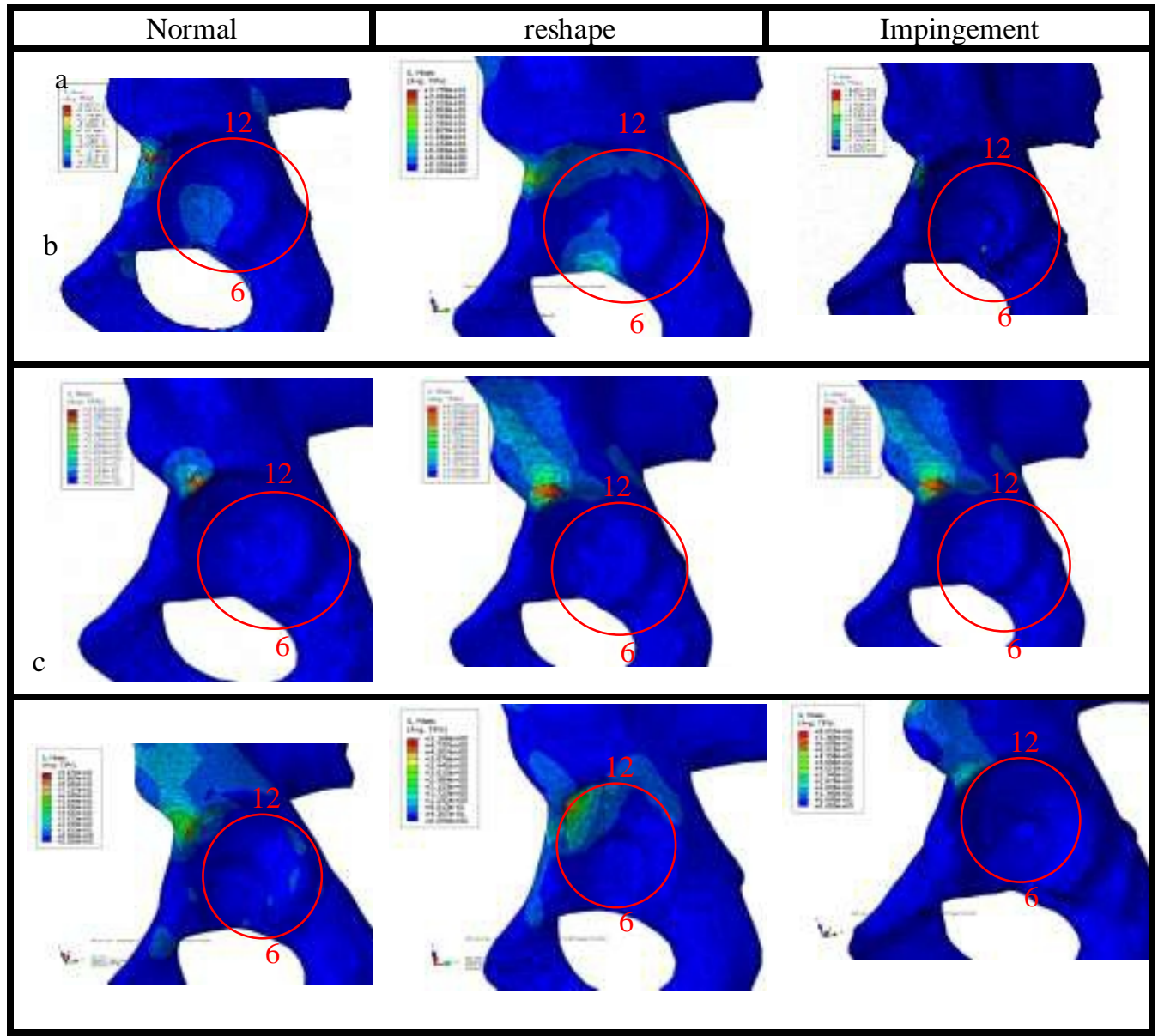

Figure 2: Comparison of impingement zone for normal, impingement and reshaped hip a) free centre of rotation b) fixed centre of rotation c) soft tissue (lateral view of left hip)

Boundary conditions are important in computer-aided programmes. The closer the boundary conditions are to the real hip, the more accurate are the results and the information is closer to the reality. Furthermore, there is a 
need for computer aided programme for a hip model without simplifications. Table 2 presents the results of flexion, adduction and internal rotation of the hip model with soft tissues. Table 2 presents the impingement angle when soft tissue was added to hip models. Further, Figure 2 shows that impingement happens at the 11 o'clock position for both hip models, with and without the soft tissues.

Table 4: The comparison of the normal hip ROM for computer-aided programme and

\begin{tabular}{cccc}
\multicolumn{4}{c}{ experimental results } \\
\hline Conditions & Flexion & Adduction & Internal Rotation \\
\hline Fixed centre of rotation & 115 & 27 & 30 \\
Free centre of rotation & 105 & 32 & 8 \\
Hip with soft tissue & 139 & 40 & 30 \\
Experiments results & 142 & 43 & 32 \\
\hline
\end{tabular}

Table 4 contains comparisons of obtained results for both the experimental and computational hip models for the normal individual. Those obtained from the hip model with soft tissues are close to the experimental results. As can be observed from Table 3, the experimental flexion result is closer to the model with the soft tissues connected to it. In addition, it is observed that the experimental model and the hip model with soft tissues register the flexion angle as being approximately $140^{\circ}$. However, the model with no soft tissues has a considerably lower flexion angle, around $115^{\circ}$. These differences can also be seen regarding adduction and internal rotation. Moreover, adduction and internal rotation for the hip model with the soft tissues and the experimental model are approximately the same.

The results obtained from the two hip models are significantly $(p \leq 0.005)$ different. This difference shows that the soft tissues could exert a massive effect with respect to the impingement angle. By including soft tissues in the model, the results are closer to the experimental results than without soft tissues and these have a large impact on the hip model. The impingement zone for both hip models is approximately the same at 11 o'clock. Soft tissues do not have effect on impingement zone.

\section{Discussion}

Previously, many researches have worked on the impingement zone and angle (Bedi, et al., 2011), (Bedi, Dolan, Magenn, Lipman, Buly, \& Kelly, 2012), (Kubiak-Langer, Tannast , Murphy, Siebenrock , \& Langlotz , 2007), (Tannast, Kubiak-Langer, Langlo, Puls , Murphy , \& Siebenrock , 2007). They have used the patient's CT scan to create their 3D model. However, none have included soft tissues as the researchers contended that impingement is an outcome of bone to bone contact.

As observed from the obtained results, in Table 2, having soft tissues attached to the model also has an effect on obtaining bigger angles. Because 
the ligaments connect the bones together and constrain the range of motion of the bone, the ligaments could act as lever arm which increase the angle. In addition, the cartilage affect the kinematics of the hip.

The boundary condition of the hip model is very important when studying the biomechanics of the hip. Moreover, as shown above in Table 2, the centre of rotation is an important parameter in hip mechanics. Previously (Kubiak-Langer, Tannast, Murphy, Siebenrock , \& Langlotz , 2007) the centre of rotation was fixed at the centre of the femur in computer aided programs in order to detect impingement. The method used in this work to find the impingement angle (flexion, adduction in $90^{\circ}$ flexion and the internal rotation in $90^{\circ}$ flexion), is quite similar to that adopted in previous studies (Kubiak-Langer, Tannast, Murphy, Siebenrock , \& Langlotz , 2007) where the centre of rotation is fixed. According to our findings, hip arthroscopy can help patients with impingement and increase their ROM.

Our results for the free centre of rotation, as shown in Table 2, are the same as those found in previous articles (Bedi, et al., 2011), (Bedi, Dolan, Magenn, Lipman, Buly, \& Kelly, 2012) and Tables 1 and 3 show that the impingement angles are similar to previously reported findings. The results in this instance are slightly lower (about $10^{\circ}$ in flexion, about $10^{\circ}$ in internal rotation) than for the fixed centre of rotation. The adduction remains the same for the both models. The impingement zone remains the same, being positioned at 11 o'clock. However in this case there is also an impingement at the 6 o'clock point, which may appear to be the consequence of the free centre of rotation, as the hip moves freely in any directions.

The complete model of the hip with soft tissues is closer to the real biological counterpart. This model with cartilage and ligaments is a complete model obtained from a specific patient. In this model, the impingement angles are higher (about $20^{\circ}$ in flexion, about $10^{\circ}$ in adduction) than the model without soft tissues. The internal rotation remains the same for both models. The impingement zone remains at the 11 o'clock point.

The important message in this study is that the centre of rotation is an important factor when attempting to detect the impingement angle. As the results of this work, it becomes clear that the soft tissues play an important role in kinematics and this might affect the impingement angle. All previous studies (Kubiak-Langer, Tannast, Murphy , Siebenrock , \& Langlotz , 2007), (Tannast, Kubiak-Langer, Langlo, Puls , Murphy , \& Siebenrock , 2007), (Bedi, et al., 2011) (Bedi, Dolan, Magenn, Lipman, Buly, \& Kelly, 2012), assumed that the centre of rotation was fixed with the centre of femur and in addition these studies (Kubiak-Langer, Tannast, Murphy, Siebenrock , \& Langlotz , 2007), (Tannast, Kubiak-Langer, Langlo, Puls , Murphy , \& Siebenrock , 2007), (Bedi, et al., 2011) (Bedi, Dolan, Magenn, Lipman, Buly, \& Kelly, 2012), did not consider the complete hip model with 
cartilage, ligaments and muscles, for impingement evaluation. Some researchers claimed that the method chosen regarding fixing the centre of rotation affects the results of the computational modelling of the hip (Arbabi, schmid, Boulic, Thalman, \& Thalman , 2012). Our results show that the point selected for the centre of rotation can change the impingement angle for the hip. Moreover, having a fixed centre or free centre of rotation has an important impact on the impingement angle.

Many computer-based simulations are used to speed up and improve the accuracy of the detection of diseases and to cure them (Arbabi, schmid, Boulic, Thalman, \& Thalman , 2012). But it should be noted that when different methods are applied to selecting the centre of rotation in hip models different values for the same hip model can be obtained (Arbabi, schmid, Boulic, Thalman, \& Thalman , 2012). Some researchers have also obtained range of values for motion when the centre of rotation is changed (Arbabi, schmid, Boulic, Thalman, \& Thalman , 2012).

\section{Conclusion}

Most of the computational models have assumed that the centre of rotation is fixed. The finding of this chapter demonstrates that the centre of rotation can have a considerable effect on impingement angle. The need in clinical study is a complete hip model without simplification and the geometry of the hip. The model should be as faithful to the true geometry as possible.

Changing the boundary conditions, changes the simulation results. One of the main boundary conditions is the centre of rotation which changes the angles obtained in the FADIR test.

Our complete hip model with soft tissues and with free centre of rotation shows slight differences in hip impingement angle in comparison to the hip model with fixed centre of rotation. However, in all cases the impingement zone remains the same. The soft tissues have an impact on impingement angle.

The ROM of hip improves after reshaping in any boundary conditions. The ROM of impinged person is lower than the ROM of normal person in any boundary conditions. Computer assistant programming including FEA could not accurately mimic the human movement and human motion analysis since the results depend on boundary condition. It is necessary to include soft tissues on hip modelling in order to have accurate kinematic results.

The limitation of the study is that the hip model needs to be completed by adding muscles to it which is possible by using accurate MRI and carrying out some image processing on the MR images. As threshold 
values for soft tissues are quite similar, image processing can be used to distinguish the soft tissues.

\section{Acknowledgements}

We thank Epsom hospital for providing the CT and MRI images of patients. There was no source of founding.

\section{References:}

1. Arbabi, E., schmid, J., Boulic, Thalman, \& Thalman , N., 2012. Sensivity of hip tissues contact evaluation to the methods used for estimating the hip joint center of rotation. Med boil eng comput, 50(6), 595-604.

2. Bagwell, J., Snibbe, J., Gerhardt, M., \& Powers, C., 2016. Hip kinematics and kinetics in persons with and without cam femoroacetabular impingement during a deep squat task. Clinical Biomechanics, 31, 87-92.

3. Beaulé, P., Zaragoza, E., Motamedi , K., Copelan , N., \& Dorey, F. J., 2005. three-dimensional computed tomography of the hip in the assessment of femoroacetabular. J Orthop Res, 23(6), 1286-1292.

4. Bedi, A., Dolan, M., Hetsroni, I., Magennis, E., Lipman, J., Buly, R., \& Kelly, B., 2011. Surgical treatment of femoroacetabular impingement improves hip kinematics : A computer-assisted model. The American Journal of Sports Medicine, 39(1), 42s-48s.

5. Bedi, A., Dolan, M., Magenn, E., Lipman, J., Buly, R., \& Kelly, B., 2012. Computer-assisted modeling of osseous impingement and resection in femoroacetabular impingement. The Journal of Arthroscopic and Related Surgery, 28(2), 204-210.

6. Brunner , A., Horisberger, M., \& Herzog , R. F., 2009. Evaluation of a computed tomography-based navigation system prototype for hip arthroscopy in the treatment of femoroacetabular cam impingement. Arthroscopy, 25(4), 382-391.

7. Chegini, S., Beck, M., \& Ferguson, S., 2009. The effects of impingement and dysplasia on stress distributions in the hip joint during sitting and walking: a finite element analysis. J Orthopaedic Research Society, 27(2), 195-201.

8. Eijer, H., Myers , S., \& Ganz , R., 2001. Anterior femoroacetabular impingement after femoral neck fractures. J Orthop Trauma, 15(7), 475-481.

9. Ganz, R., Parvizi, J., Beck, M., Leunig, M., Nötzl, H., \& Siebenrock, K., 2003. Femoroacetabular impingement: a cause for osteoarthritis of the hip. Clinical orthopaedics and related research, 417, 112-120. 
10. Hu , Q., Langlotz , U., Lawrence , J., Langlotz , F., \& Nolte , L., 2001. A fast impingement algorithm for computer-aided orthopaedic surgery. Comput Aided Surg, 16(2), 104-110.

11. Jäger , M., Wild , A., Westhoff , B., \& Krauspe, R., 2004. Femoroacetabular impingement caused by a femoral osseous headneck bump deformity: clinical, radiological, and experimental results. J Orthop Sci, 9(3), 256-263.

12. Kang , M., Sadri, H., Moccozet, L., \& Magnenat-Thalmann , N., 2002. Accurate simulation of hip joint range of motion. (pp. 215219). CA: Proceedings of IEEE Computer Animation.

13. Kennedy , M. J., Lamontagne, M., \& Beaulé , P. E., 2009. Femoroacetabular impingement alters hip and pelvic biomechanics during gait walking biomechanics of FAI. Gait \& Posture, 30(1), 4144.

14. Kubiak-Langer, M., Tannast , M., Murphy , S., Siebenrock , K., \& Langlotz , F., 2007. Range of motion in anterior femoroacetabular impingement. Clinical orthopaedics and related research, 458, 117124.

15. Lavigne , M., Parvizi , J., Beck, M., Siebenrock , K., Ganz, R., \& Leuning, M., 2004. Anterior femoroacetabular impingement. Part I: techniques of joint preserving surgery. Clin Orthop Relat Res, 418, 61-66.

16. Leunig, M., Podeszwa , D., Beck , M., Werlen , S., \& Ganz, R., 2004. Magnetic resonance arthrography of labral disorders in hips with dysplasia and impingement. Clin Orthop Relat Res, 418, 74-80.

17. Lin , M. C., \& Manocha, D., 1995. Fast interference detection between geometric models. The Visual Computer, 11(10), 542-561.

18. Mantovani, G., Ng, G., \& Lamo, M., 2016. Regression models to predict hip joint centers in pathological hip population. Gait \& Posture, 44, 48-54.

19. Monahan , E., \& Shimada , K., 2008. Verifying the effectiveness of a computeraided navigation system for arthroscopic hip surgery. Stud Health Technol Inform, 132, 302-307.

20. Moore, M., \& Wilhelms, O., 1988. Collision detection and response response for computer animation. Computer graphics and interactive techniques, 22(4), 289 -298.

21. Pearle, A. D., Kendoff , D., \& Musahl , V., 2009. Perspectives on computer-assisted orthopaedic surgery: movement toward quantitative orthopaedic surgery. J Bone Joint Surg Am, 91(1), 7-12.

22. Philips , A. T., Pankaj , P., Howie , C. R., Usmani , A. S., \& Simpson, A. H., 2007. Finite element modelling of the 
pelvis:inclusion of muscular and ligamentous boundary conditions. medical engineering and physics, 29(7), 739-748.

23. Rivkin , G., \& Liebergall , M., 2009. Challenges of technology integration and computer-assisted surgery. J Bone Joint Surg Am, 91(1), 13-16.

24. Russell, M. E., Shivanna, K. H., Grosland, N. M., \& Pedersen, D. R., 2006. Cartilage Contact Pressure Elevations in Dysplastic Hips: A Chronic Overload Model. Journal of Orthopaedic Surgery and Research, 1(6), 5-11.

25. Siebenrock , K., Schöniger , R., \& Ganz , R., 2003. Anterior femoroacetabular impingement due to acetabular retroversion: treatment with periacetabular osteotomy. J Bone Joint Surg Am, 85(A(2)), 278286.

26. Strehl , A., \& Ganz , R., 2005. Anterior femoroacetabular impingement after healed femoral neck fractures. Unfallchirurg, 108(4), 263-273.

27. Tannast , M., Langlotz , U., Siebenrock, K., Wiese, M., Bernsmann , K., \& Langlotz , F., 2005. Anatomic referencing of cup orientation in total hip arthroplasty. Clin Orthop Relat Res, 436, 144-150.

28. Tannast, M., Goricki, D., Beck, M., Murphy, S. B., \& Siebenrock, K. A., 2008. Hip damage occurs at the zone of femoroacetabular impingement. Clin Orthop Relat Res, 466(2), 273-280.

29. Tannast, M., Kubiak-Langer, M., Langlo, F., Puls , M., Murphy, S., \& Siebenrock , K., 2007. Non-invasive three-dimensional assessment of femoroacetabular impingement. Journal of orthopaedic research, 25(1), 122-131.

30. Wettstein , M., \& Dienst , M., 2006. Hip arthroscopy for femoroacetabular impingement. Orthopad, 35(1), 85-93. 